Article

\title{
High-Gossypol Whole Cottonseed Exhibited Mediocre Rumen Degradability and Less Microbial Fermentation Efficiency than Cottonseed Hull and Cottonseed Meal with an In Vitro Gas Production Technique
}

\author{
Weikang Wang (D), Qichao Wu, Wenjuan Li, Yanlu Wang, Fan Zhang, Liangkang Lv, Shengli Li \\ and Hongjian Yang * (D)
}

check for updates

Citation: Wang, W.; Wu, Q.; Li, W.; Wang, Y.; Zhang, F.; Lv, L.; Li, S.; Yang, H. High-Gossypol Whole Cottonseed Exhibited Mediocre Rumen Degradability and Less Microbial Fermentation Efficiency than Cottonseed Hull and Cottonseed Meal with an In Vitro Gas Production Technique. Fermentation 2022, 8, 103. https://doi.org/ $10.3390 /$ fermentation 8030103

Academic Editor: Mohammad Taherzadeh

Received: 3 February 2022 Accepted: 25 February 2022 Published: 28 February 2022

Publisher's Note: MDPI stays neutral with regard to jurisdictional claims in published maps and institutional affiliations.

Copyright: (C) 2022 by the authors. Licensee MDPI, Basel, Switzerland. This article is an open access article distributed under the terms and conditions of the Creative Commons Attribution (CC BY) license (https:// creativecommons.org/licenses/by/ $4.0 /)$.
State Key Laboratory of Animal Nutrition, College of Animal Science and Technology, China Agricultural University, Beijing 100193, China; B20183040344@cau.edu.cn (W.W.); wuqichao@cau.edu.cn (Q.W.); b20193040342@cau.edu.cn (W.L.); wang_yanlu@cau.edu.cn (Y.W.); zhangfan@cau.edu.cn (F.Z.); b20213040345@cau.edu.cn (L.L.); lishengli@cau.edu.cn (S.L.)

* Correspondence: yang_hongjian@sina.com

\begin{abstract}
To explore whether or not the gossypol varied in cottonseed by-products affect rumen degradability and fermentation efficiency, an in vitro cumulative gas production experiment was applied with mixed rumen microorganism to compare rumen fermentation characteristics of whole cottonseed (WCS, $n=3$ samples), cottonseed meal (CSM, $n=3$ samples), and cottonseed hull (CSH, $n=2$ samples). The five-replicate fermentation per sample per incubation time continuously lasted for $0.5,1.5,3,6,12,24,36$, and $48 \mathrm{~h}$ with an automated gas production recording system. Regardless of distinct nutrient differences, the free gossypol level in these cottonseed by-products ranked: WCS $>\mathrm{CSH}>\mathrm{CSM}$. After $48 \mathrm{~h}$ of incubation, the in vitro dry matter degradability and ammonia $\mathrm{N}$ concentration ranked as: $\mathrm{CSM}>\mathrm{WCS}>\mathrm{CSH}$. The cumulative gas production and total volatile fatty acid (VFA) levels in the culture fluids ranked: CSM > CSH > WCS, in which the average production rate ranked: CSM > WCS > CSH. Regarding the molar VFA pattern, WCS in comparison with CSH and CSM presented the lowest production of non-glucogenic acids (e.g., acetate) and exhibited the highest fermentation efficiency of energy from carbohydrates to VFAs. There was a significant negative correlation between the gossypol content and cumulative gas and total VFA production, suggesting that the greater gossypol in cottonseed by-products, the more detrimental effect occurred for rumen fermentation. In a brief, WCS exhibited mediocre rumen degradability and less microbial fermentation efficiency than CSH and CSM, depending on their gossypol levels.
\end{abstract}

Keywords: cottonseed by-products; gossypol; in vitro incubation; gas production kinetics; ruminal fermentation characteristics

\section{Introduction}

Cottonseed and its by-products are frequently used as an energy and protein feed resource in dairy cows, though they contain free gossypol (FG), a polyphenolic compound produced by cotton [1]. Although rumen microbes have been demonstrated to be capable of gossypol biodegradation ability [2-5], excessive intake of FG from rations will be toxic to animal [6-9]; many studies have shown that feed ruminants with cottonseed and its by-products containing a high content of gossypol would increase the incidence of abortion and somatic cell score in milk and decrease the quantity of viable ovarian follicles, semen quality, milk production, and milk protein [10-15]. All of these studies on cottonseed and its by-products were mainly based on their feeding effect on the production and reproduction performance of ruminants, but there is limited information about their gas production kinetics and rumen microbial fermentation characteristics. 
In a previous study, we investigated the rumen degradation characteristics and bacteria colonization of different cottonseeds and their by-products by in situ incubation; it revealed that the level of neutral detergent fiber, ether extract, and FG in cotton by-products were significantly related with the composition of the attached bacteria; however, the rumen fermentation efficiency of these cottonseed by-products was not determined due to the fluidity of the rumen environment [16]. The in vitro gas production technique proposed by Menke et al. [17] initially used a mixed rumen microorganism as the inoculant to evaluate the digestibility of tested feed materials in terms of cumulative gas production, ammonia $\mathrm{N}$, and volatile fatty acids production. To some extent, this in vitro fermentation method can reflect the rumen degradation extent of feed materials indirectly. Compared with the in vivo animal trial, the in vitro gas production technique, to a large extent, avoided the influence of individual animal differences, nutrient absorption by the rumen wall, and rumen outflow rate. In a previous study, it revealed that gossypol had a detrimental effect on the population of proteolytic bacteria and fungi by an in vitro gossypol addition experiment [18]. However, there has been no research conducted to investigate whether or not the gossypol varied in cottonseed by-products affect rumen degradability and fermentation efficiency.

In summary, it is of great importance to evaluate the effects of gossypol on fermentation parameters for the safe feeding amount of cottonseed by-products. The objectives of the present study were to determine the gas production kinetics and in vitro rumen fermentation characteristics of cottonseed and its by-products and investigate the effect of gossypol on ruminal microbial fermentation.

\section{Materials and Methods}

\subsection{Experimental Design}

For each treatment, $500 \mathrm{mg}$ of cottonseed and its by-product samples were individually weighed into a 120-mL glass bottle. Each bottle was filled with 50-mL buffer solution [19] and $25-\mathrm{mL}$ filtered rumen liquid. Afterwards, all of these bottles $(8$ samples $\times 5$ fermentation $\times 8$ incubation time) were purged with anaerobic $\mathrm{N}_{2}$ to obtain an anaerobic condition and sealed with butyl rubber stoppers and Hungate's screw caps, then were individually connected to an automated gas production recording system (AGRS-III, China Agricultural University, Beijing, China) and incubated at $39{ }^{\circ} \mathrm{C}$ for $0.5,1.5,3,6,12,24,36$, and $48 \mathrm{~h}$.

\subsection{Cottonseed and Cottonseed By-Products}

Representative cottonseed and its by-product samples of Xinluzao, an early maturing upland cotton variety, were collected from Xinjiang Uygur Autonomous Region of China, including three whole cottonseed (WCS) samples, three cottonseed meal (CSM) samples, and two lint cottonseed hull (CSH) samples. All samples were dried at $65{ }^{\circ} \mathrm{C}$ for $24 \mathrm{~h}$ in a forced air oven, ground to pass through a $2.00-\mathrm{mm}$ screen, and stored prior to chemical analysis and in vitro incubation. The chemical compositions of three kinds of tested samples are shown in Table 1.

Table 1. Nutrient compositions and free gossypol (FG) contents of cottonseed and its by-products (g/kg DM).

\begin{tabular}{cccccc}
\hline Item $^{\mathbf{1}}$ & CP & ADF & NDF & EE & FG \\
\hline CSH & $71^{\mathrm{c}}$ & $579^{\mathrm{a}}$ & $806^{\mathrm{a}}$ & $24^{\mathrm{b}}$ & $0.57^{\mathrm{b}}$ \\
CSM & $490^{\mathrm{a}}$ & $139^{\mathrm{c}}$ & $173^{\mathrm{c}}$ & $12^{\mathrm{b}}$ & $0.27^{\mathrm{b}}$ \\
WCS & $217^{\mathrm{b}}$ & $360^{\mathrm{b}}$ & $502^{\mathrm{b}}$ & $158^{\mathrm{a}}$ & $4.66^{\mathrm{a}}$ \\
SEM & 11.2 & 40.1 & 32.8 & 24.2 & 1.19 \\
$p$-value & $<0.01$ & $<0.01$ & $<0.01$ & $<0.01$ & $<0.01$ \\
\hline
\end{tabular}

${ }^{1} \mathrm{CP}$, Crude protein; ADF, acid detergent fiber; NDF, neutral detergent fiber; EE, Ether extract; CSH, Cottonseed hull; CSM, Cottonseed meal; WCS, Whole cottonseed. SEM, standard error of the difference of the means, $n=3$. $a, b, c$ Values in a column within the same class without a common superscript are significantly different $(p<0.05)$. 


\subsection{Rumen Liquid Preparation}

Three rumen-fistulated lactating Holstein cows (average body weight: $517 \pm 25 \mathrm{~kg}$, 125 days in milk, and $36 \mathrm{~kg} / \mathrm{d}$ of milk yield at the beginning of the study) were used as rumen liquid donors. The cows had free access to water and drink and were daily fed with $25 \mathrm{~kg}$ of dry matter (DM) of a total mixed ration consisting of $500 \mathrm{-g} / \mathrm{kg}$ maize silage, $110-\mathrm{g} / \mathrm{kg}$ alfalfa hay, $140-\mathrm{g} / \mathrm{kg}$ maize meal, and $250 \mathrm{-g} / \mathrm{kg}$ commercial concentrate. Rumen liquid was collected one hour after morning feeding and squeezed through four layers of cheesecloth. The filtrated rumen liquids of each cow were mixed in equal proportions. All animal experimental procedures were conducted in accordance with the in situ Animal Care Committee of China Agricultural University (CAU20171014-1).

\subsection{In Vitro Rumen Incubation Procedure}

After each incubation period was completed, the corresponding bottles were disconnected from the AGRS-III system. The remaining biomass of each bottle was separately filtered through pre-weighed nylon bags. The bags containing filtrated residues were then rinsed in tap water until the water ran clear, then squeezed by hand to remove excess water and dried at $65{ }^{\circ} \mathrm{C}$ for $24 \mathrm{~h}$ for the in vitro dry matter disappearance (IVDMD) analysis. One sample of 1-mL culture fluid from each bottle was mixed with $0.3 \mathrm{~mL}$ of $250-\mathrm{g} / \mathrm{L}$ metaphosphoric acid solution at $4{ }^{\circ} \mathrm{C}$ for $30 \mathrm{~min}$ and centrifuged at $10,000 \times g$ for $15 \mathrm{~min}$ at $4{ }^{\circ} \mathrm{C}$. The supernatants were kept at $-20{ }^{\circ} \mathrm{C}$ for the later analysis of volatile fatty acids (VFAs) and ammonia N.

\subsection{Chemical Analysis and Calculations}

Nitrogen $(\mathrm{N})$ was analyzed using a Kjeldahl distiller according to the standard methods of AOAC [20], and crude protein (CP) was calculated as $6.25 \times \mathrm{N}$. Ether extract (EE) was determined using light petroleum ether in the Soxhlet apparatus, according to the standard methods of AOAC [20]. Neutral detergent fiber (NDF) and acid detergent fiber (ADF) were determined according to the procedures of Van Soest et al. [21], which were modified for an Ankom 2000 Fiber Analyzer (Ankom Technol. Corp., Fairport, NY, USA), using heat-stable $\alpha$-amylase and sodium sulfite for NDF analysis. The ammonia $\mathrm{N}$ concentration was determined by spectrophotometry according to the method of Verdouw et al. [22].

The in vitro disappearance $(Y)$ of dry matter at a time $(t)$ was fitted to an exponential model by an iterative regression analysis [23] using the nonlinear (NLIN) procedure of SAS [24]. The model is described by Equation (1):

$$
Y=a+b \times\left(1-e^{-c \times t}\right)
$$

where ' $e$ ' is the base of a natural logarithm, the constant ' $a$ ' represents the soluble and very rapidly degradable component, and ' $b$ ' represents the insoluble but potentially degradable component, which has a constant degradation rate $(c)$ per unit time.

The VFA concentration and fermentation gas composition were determined by gas chromatography according to the methods of Zhang and Yang [25] and Cui et al. [26], respectively.

Cumulative GP data $(G P(t), \mathrm{mL} / \mathrm{g} \mathrm{DM})$ at time $(t)$ were fitted to a nonlinear model by iterative regression analysis, as shown in Equation (2):

$$
G P(t)=A /\left[1+(C / t)^{B}\right]
$$

where $A$ represents the asymptotic GP generated at a constant fractional rate $(c)$ per unit time, $t$ is the time of the gas recording, $B$ is a sharpness parameter determining the shape of the curve, and $C$ is the time (h) at which half of $A$ is reached. The value of $A-C$ was estimated using the nonlinear procedure of SAS. The average GP rate (AGPR) at half of $A$ was calculated according to Equation (3):

$$
A G P R=(A \times B) /(4 \times C)
$$


Isobutyrate and isovalerate were summed as branched-chain VFAs (BCVFA). The ratio of non-glucogenic-to-glucogenic acids (NGR) was calculated as Equation (4):

$$
N G R=(\text { acetate }+2 \times \text { butyrate }+ \text { valerate }) /(\text { propionate }+ \text { valerate })
$$

where the VFAs were expressed in molar proportions.

The fermentation efficiency (FE) of energy from carbohydrates to VFAs was estimated using Equation (5):

$$
F E=\frac{0.622 \times \text { acetate }+1.092 \times \text { propionate }+1.56 \times \text { butyrate }}{\text { acetate }+ \text { propionate }+2 \times \text { butyrate }}
$$

\subsection{Gossypol Extraction and High-Performance Liquid Chromatography Analysis}

Free gossypol was extracted according to the method described by Wang et al. [16]. One-and-a-half grams of sample were ultrasound $30 \mathrm{~min}$ at $40{ }^{\circ} \mathrm{C}$ in $15-\mathrm{mL}$ acetone, centrifuged with the speed of $1000 \times g$ at $25^{\circ} \mathrm{C}$ for $10 \mathrm{~min}$, and collected the supernatant; repeat the above process three times; the extraction was combined and filtrated with $0.45-\mu \mathrm{m} \mathrm{mi-}$ croporous, rotary evaporated, and dissolved by acetonitrile- $0.2 \%$ phosphoric acid solution, with a fixed capacity at $2.5 \mathrm{~mL}$.

The contents of FG were quantified by high-performance liquid chromatography using a Wufeng analytical instrument (Wufeng Co. Ltd., Shanghai, China) consisting of an LC-P100PLUS pump, LC-UV100PLUS UV detector, LC-CO100PLUS column heater, and a symmetry reversed-phase C18 column $(250 \times 4.6 \mathrm{~mm}, 5 \mu \mathrm{m}, \mathrm{pH} 2-8$, Waters, Milford, MA, USA). The method was set as follows: The mobile phase was acetonitrile $-0.2 \%$ phosphoric acid solution $(v / v$ : 85/15) under a flow rate of $1 \mathrm{~mL} / \mathrm{min}$. The injection was $20 \mu \mathrm{L}$, and gossypol was detected at $235 \mathrm{~nm}$ with an analysis temperature at $25^{\circ} \mathrm{C}$.

The gossypol standard curve was made according to the method of Wang et al. [18] as follows: an amount of 100-mg standard gossypol was dissolved into $1 \mathrm{~mL}$ of the mobile phase and diluted to $100,50,25,12.5,6.25,3.125,1.55,0.78,0.36,0.18$, and $0.09 \mu \mathrm{g} / \mathrm{mL}$ by the mobile phase. The standard curve (Figure 1) was obtained by linear regression of the peak area $(\mathrm{Y})$ and gossypol concentration $(\mathrm{X})$ under optimal chromatographic conditions, as noted above. The gossypol standards were shown to peak at a retention time of $5 \mathrm{~min}$.

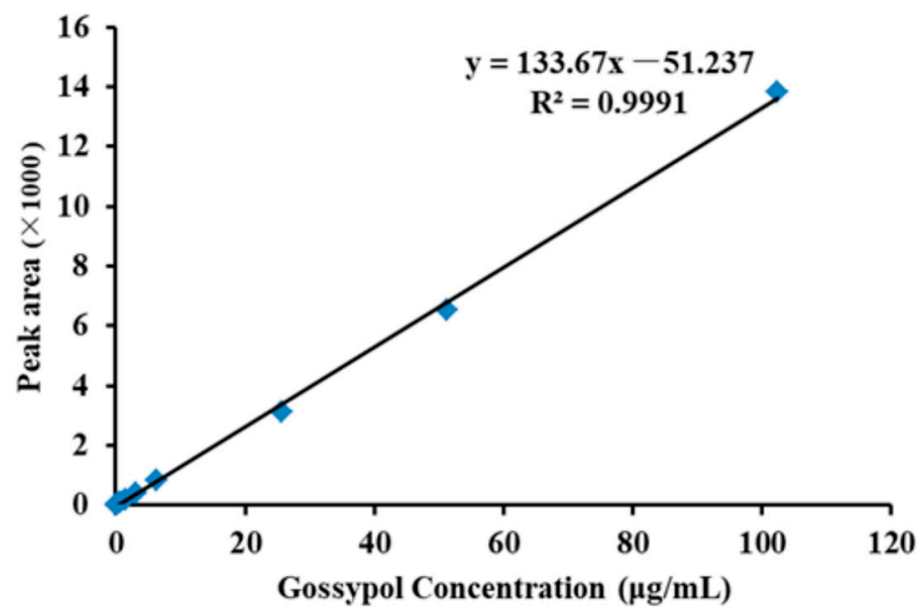

Figure 1. Standard curve of gossypol.

\subsection{Statistic Analysis}

The data collected were tested for normal distribution using the Shapiro-Wilk test. The data was normally distributed, and statistical analyses were performed by using the general linear model procedure of SAS (1999) with a multiple comparison test (Turkey/Kramer). For data that lacked a normal distribution, statistical analyses were performed using 
a Kruskal-Wallis test (Proc npar1way). Significance was declared at $p<0.05$, unless otherwise noted.

\section{Results and Discussions}

\subsection{In Vitro Dry Matter Degradability}

Dry matter degradability is an important index that can reflect the degradation extent of feed in the rumen. In the current study, the IVDMD of all samples increased significantly before $24 \mathrm{~h}$, and the degradation speed slowed down after $24 \mathrm{~h}$. The IVDMD at $48 \mathrm{~h}$ ranked as: CSM > WCS > CSH (Table 2), and it was consistent with the in vivo results of Wang et al. [16], which noted that the results of in vitro incubation were reliable compared with in situ. In the first $0.5 \mathrm{~h}$, degradation rate of WCS was faster than CSM, but IVDMD was greater in CSM than WCS after $1.5 \mathrm{~h}(p<0.01)$, and it can be explained by the results of the degradation kinetic analysis (Table 2), which showed that WCS presented a more rapidly degradable component (a). Meanwhile, CSM presented the highest total degradable component content $(\mathrm{a}+\mathrm{b})$ and constant degradation rate $(\mathrm{c})$, suggesting it was more readily degraded in the rumen than WCS and CSH. Generally, the higher content of protein and lower content of the fiber resulted in greater dry matter degradability; therefore, IVDMD was remarkably lower in CSH than WCS and CSM $(p<0.01)$ in the whole incubation period. The correlation analysis showed that the FG content in cottonseed and its by-products presented a poor correlation with IVDMD, which noted that the digestibility varied mainly depending on the difference of the nutritional nature in feeds rather than the effect of the gossypol content.

Table 2. In vitro dry matter degradability of cottonseed and its by-products.

\begin{tabular}{|c|c|c|c|c|c|}
\hline Item $^{1}$ & $\mathrm{CSH}$ & CSM & WCS & SEM & $p$-Value \\
\hline \multicolumn{6}{|c|}{ Disappearance at Different Incubation Time (\%) } \\
\hline $0.5 \mathrm{~h}$ & $4.35^{b}$ & $17.31^{\mathrm{a}}$ & $19.80^{a}$ & 1.37 & $<0.01$ \\
\hline $1.5 \mathrm{~h}$ & $5.16^{c}$ & $23.90^{a}$ & $18.68^{b}$ & 0.78 & $<0.01$ \\
\hline $3 \mathrm{~h}$ & $9.57^{b}$ & $31.13^{\mathrm{a}}$ & $28.42^{\mathrm{a}}$ & 1.58 & $<0.01$ \\
\hline $6 \mathrm{~h}$ & $10.55^{c}$ & $41.64^{a}$ & $36.91^{b}$ & 1.37 & $<0.01$ \\
\hline $12 \mathrm{~h}$ & $16.36^{c}$ & $60.94^{a}$ & $45.85^{b}$ & 1.51 & $<0.01$ \\
\hline $24 \mathrm{~h}$ & $28.83^{c}$ & $76.93^{a}$ & $56.40^{b}$ & 1.61 & $<0.01$ \\
\hline $36 \mathrm{~h}$ & $32.15^{c}$ & $76.14^{a}$ & $60.80^{b}$ & 1.59 & $<0.01$ \\
\hline $48 \mathrm{~h}$ & $38.86^{c}$ & $79.81^{\mathrm{a}}$ & $59.10^{b}$ & 1.71 & $<0.01$ \\
\hline \multicolumn{6}{|c|}{ Degradation Kinetic } \\
\hline $\mathrm{a}$ & $0.04^{b}$ & $0.13^{\mathrm{a}}$ & $0.15^{\mathrm{a}}$ & 0.02 & $<0.05$ \\
\hline $\mathrm{b}$ & 0.53 & 0.66 & 0.44 & 0.09 & 0.33 \\
\hline C & $0.02^{b}$ & $0.10^{\mathrm{a}}$ & $0.09^{\mathrm{a}}$ & 0.007 & $<0.01$ \\
\hline
\end{tabular}

${ }^{1} \mathrm{CSH}$, Cottonseed hull; CSM, Cottonseed meal; WCS, Whole cottonseed; a, soluble and very rapidly degradable component; $b$, insoluble but potentially degradable component; $c$, a constant degradation rate per unit time of $b$; SEM, standard error of the difference of the means, $n=3$. ${ }^{a, b, c}$ Values in a column within the same class without a common superscript are significantly different $(p<0.05)$.

\subsection{Gas Production Kinetics}

Cumulative gas production is positively related to the degradability of the organic substance, and fermentation gas produced from the rumen mainly resulted from the digestion of soluble carbohydrate [17]. The AGRS-III system used in the present study was capable of continuously recording cumulative gas production the whole time by the principle of pressure sensors and automatic generated gas production curves according to the gas production at different incubation times, which reflected the dynamic degradation characteristics of the tested feed resource directly.

In the present study, cumulative gas production at $48 \mathrm{~h}$ ranked as follows: CSM $>\mathrm{CSH}$ $>$ WCS $(p<0.01)$ (Figure 2a), suggesting that CSM presented the highest content of soluble carbohydrate among three kinds of samples. Raji et al. [27] compared the in vitro gas 
production characteristics of WCS and cottonseed cake and found that the cumulative gas production of WCS and cottonseed cake reached 40 and $115 \mathrm{~mL} / \mathrm{g}$ at $24 \mathrm{~h}$, respectively, so it was much lower than the results in the current study. They did not provide information on the gossypol contents in the samples, so it was uncertain if there might be an inhibitory effect of a high gossypol content. Meanwhile, we speculated this difference might also be due to the methodological accuracy to record gas production. The average gas production rate ranked as: CSM $>$ WCS $>\mathrm{CSH}(p<0.01)$ (Table 3), and it was consistent with the constant degradation rate of dry matter, but contrary to the time at which half of the maximum gas production was reached, such results noted that CSM presented a faster fermentation speed in the rumen than WCS and CSH. According to the results of the correlation analysis, the FG content was highly negative associated with cumulative gas production $(r=-0.77, p=0.02)$ (Figure $2 b)$, and the inhibition was more obvious when the gossypol content exceeded $2 \mathrm{~g} / \mathrm{kg}$, suggesting that there was a detrimental effect of the high gossypol content originating from cottonseed and its by-products on their rumen microbial fermentation efficiency.

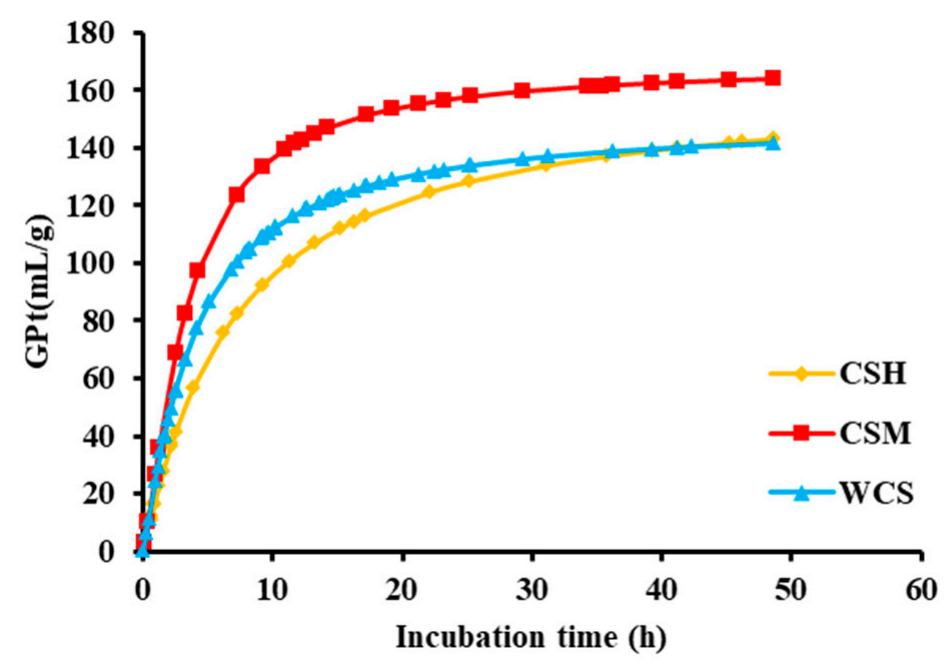

(a)

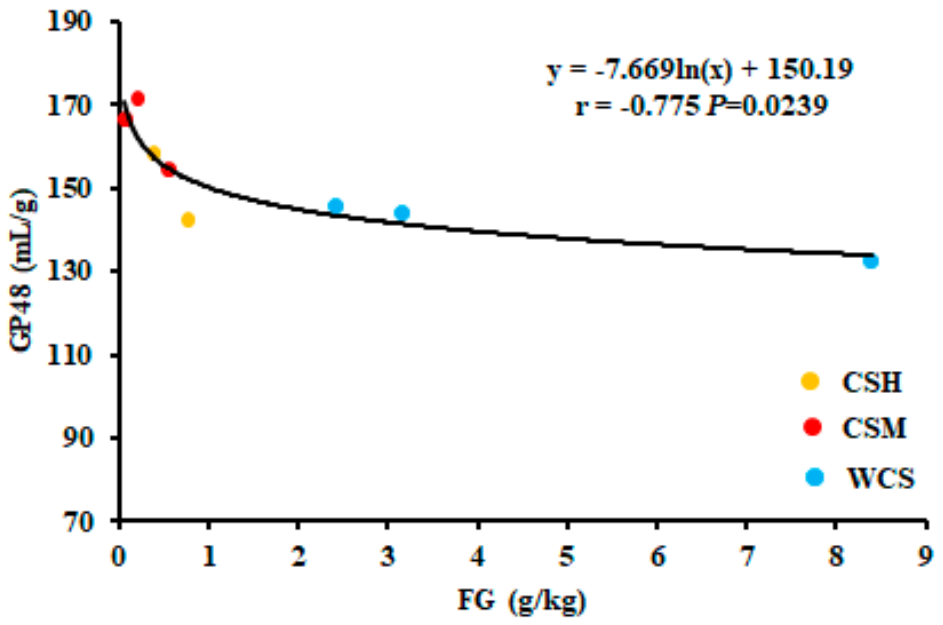

(b)

Figure 2. (a) Gas production curve of cottonseed and its by-products. (b) Correlation analysis of the free gossypol content and gas production. GP, gas production; FG, free gossypol. 
Table 3. Gas production kinetic parameters of cottonseed and its by-products.

\begin{tabular}{cccccc}
\hline Item $^{\mathbf{1}}$ & $\mathbf{G P}_{\mathbf{4 8}}$ & $\mathbf{A}$ & $\mathbf{B}$ & $\mathbf{C}$ & AGPR \\
\hline CSH & $150.3^{\mathrm{b}}$ & $161.8^{\mathrm{a}}$ & $1.05^{\mathrm{c}}$ & $7.02^{\mathrm{a}}$ & $6.14^{\mathrm{c}}$ \\
CSM & $165.1^{\mathrm{a}}$ & $168.8^{\mathrm{a}}$ & $1.32^{\mathrm{a}}$ & $3.37^{\mathrm{b}}$ & $16.68^{\mathrm{a}}$ \\
WCS & $141.5^{\mathrm{c}}$ & $149.2^{\mathrm{b}}$ & $1.16^{\mathrm{b}}$ & $3.9^{\mathrm{b}}$ & $11.24^{\mathrm{b}}$ \\
SEM & $2.7^{\mathrm{b}}$ & $3.42^{\mathrm{b}}$ & 0.01 & 0.21 & 0.41 \\
$p$-value & $<0.01$ & $<0.01$ & $<0.01$ & $<0.01$ & $<0.01$ \\
\hline
\end{tabular}

${ }^{1} \mathrm{CSH}$, Cottonseed hull; CSM, Cottonseed meal; WCS, Whole cottonseed; $\mathrm{GP}_{48}$, Cumulative gas yield of $48 \mathrm{~h}$ $(\mathrm{mL} / \mathrm{g}, \mathrm{DM})$. (A) The ideal maximum gas production $(\mathrm{mL} / \mathrm{g}, \mathrm{DM})$. (B) The sharpness for the gas production curve. (C) The time at which half of $A$ is reached (h). (AGPR) The gas production speed when the gas production is $1 / 2$ of the maximum $(\mathrm{mL} / \mathrm{h})$. SEM, standard error of the difference of the means, $n=3 .{ }^{a, b, c}$ Values in a column within the same class without a common superscript are significantly different $(p<0.05)$.

\subsection{Ammonia N}

Ammonia $\mathrm{N}$ is the intermediate digestion product of $\mathrm{CP}$ in the rumen, as well as $\mathrm{N}$ for the synthesis of microbial protein. A higher ammonia $\mathrm{N}$ concentration implicates a higher rumen degradability of protein and less portion of protein digestion in the abomasum and small intestine, and this is detrimental to the utilization of high-quality protein by host animals. Appropriate protein degradation in the rumen is conductive to make the most use of the synthesis function of rumen microorganisms and decrease the protein resource waste and nitrogen emission [28,29].

In the present study, the ammonia $\mathrm{N}$ concentration of all the fermentations increased mainly from 6 to $36 \mathrm{~h}$, in which the ammonia N yield of CSM was greater than that of WCS, and the lowest occurred in CSH throughout whole incubation time $(p<0.01)$. After $48 \mathrm{~h}$, the ammonia N level ranked as: CSM > WCS > CSH, depending on their protein levels (Table 4), and this was consistent with the IVDMD. The correlation analysis noted that the gossypol content did not affect the ammonia $\mathrm{N}$ level, and it was consistent with the results of Hou [30] and Bagheri and Batistel [31], who found that there was no difference in the ammonia N of CSM and WCS with different gossypol contents. In a previous study, we found that the population of Prevotella ruminicola, a main proteolytic bacteria in the rumen, decreased significantly when the gossypol addition content reached $0.75 \mathrm{mg} / \mathrm{g}$ [18] However, the results of the present study revealed that there was a poor correlation between the gossypol content and ammonia $\mathrm{N}$ production, and we speculated that the promoting effect of protein in the current samples was greater than the inhibitory effect of gossypol on proteolytic bacteria, which may weaken the detrimental effect of gossypol on ammonia $\mathrm{N}$ production.

Table 4. Ammonia $\mathrm{N}$ concentration of cottonseed and its by-products by in vitro fermentation $(\mathrm{mg} / \mathrm{dL})$.

\begin{tabular}{|c|c|c|c|c|c|c|c|c|}
\hline Item $^{1}$ & $0.5 \mathrm{~h}$ & $1.5 \mathrm{~h}$ & $3 \mathrm{~h}$ & $6 \mathrm{~h}$ & $12 \mathrm{~h}$ & $24 \mathrm{~h}$ & $36 \mathrm{~h}$ & $48 \mathrm{~h}$ \\
\hline $\mathrm{CSH}$ & $16.46^{b}$ & $16.82^{b}$ & $16.98^{c}$ & $18.4^{b}$ & $25.94^{c}$ & $38.27^{c}$ & $49.6^{c}$ & $51.54^{\mathrm{c}}$ \\
\hline CSM & $17.13^{a b}$ & $18.73^{a}$ & $21.08^{a}$ & $25.45^{\mathrm{a}}$ & $39.85^{a}$ & $70.95^{a}$ & $74.81^{\mathrm{a}}$ & $76.29^{a}$ \\
\hline WCS & $17.51^{\mathrm{a}}$ & $18.57^{a}$ & $19.62^{b}$ & $24.98^{\mathrm{a}}$ & $33.3^{b}$ & $56.29^{b}$ & $65.73^{b}$ & $63.68^{b}$ \\
\hline SEM & 0.30 & 0.18 & 0.23 & 0.33 & 0.84 & 1.47 & 1.18 & 1.41 \\
\hline$p$-Value & $<0.01$ & $<0.01$ & $<0.01$ & $<0.01$ & $<0.01$ & $<0.01$ & $<0.01$ & $<0.01$ \\
\hline
\end{tabular}

${ }^{1} \mathrm{CSH}$, Cottonseed hull; CSM, Cottonseed meal; WCS, Whole cottonseed; SEM, standard error of the difference of the means, $n=3$. a,b,c Values in a column within the same class without a common superscript are significantly different $(p<0.05)$.

\subsection{Volatile Fatty Acids}

Volatile fatty acids are the main production of carbohydrate decomposed by rumen microorganisms, which can be absorbed by the rumen epithelium directly. Acetate and butyrate are essential VFAs for the synthesis of milk fat, while propionate is mainly used for the synthesis of milk lactose and body fat, as well as the precursor of gluconeogenesis, 
which is the main source of glucose in ruminants. Consequently, VFAs are not only the material for the synthesis of animal products but also the main energy supply form of host ruminants [32].

In the current study, the acetate concentration was higher in CSM and CSH than WCS $(p<0.01)$, and butyrate and valerate were less in CSH than WCS and CSM $(p<0.01)$ (Figure 3). A relatively high molar proportion of acetate and butyrate occurred with CSM, which suggested that the inclusion of CSM in the diet could serve as a supply for the synthesis of milk fat. With the prolongation of the incubation time, the molar acetate proportion in CSH, CSM, and WCS decreased 0.05, 0.06, and 0.09, respectively, while the molar propionate proportion increased $0.03,0.02$, and 0.04 , respectively, suggesting that the fermentation pattern of cottonseed and its by-products shifted from acetate fermentation to propionate fermentation later in the incubation, and it could provide the host animals with more of the precursor for gluconeogenesis. Acetate and butyrate have cellulose and hemicellulose as major precursors, these fibrous carbohydrates have a slower digestion rate than non-fiber carbohydrates. Consequently, CSH presented more fiber content, which resulted in slower acetate and butyrate production rates in the present study. In dietary gossypol supplement research, Wang et al. [33] found that gossypol supplementation significantly increased the molar proportion of acetate in sheep rumen fluid. In the current study, WCS presented the highest gossypol content with the lowest acetate production, but it had the highest molar proportion of acetate in the total VFAs, which was consistent with the results of Wang et al. [33]. Acetate is the main fermentation product of structural carbohydrate, and this promoting effect of gossypol on acetate production could be explained by the promoting the effect of gossypol on fibrolytic bacteria revealed by our previous in vitro study [18].

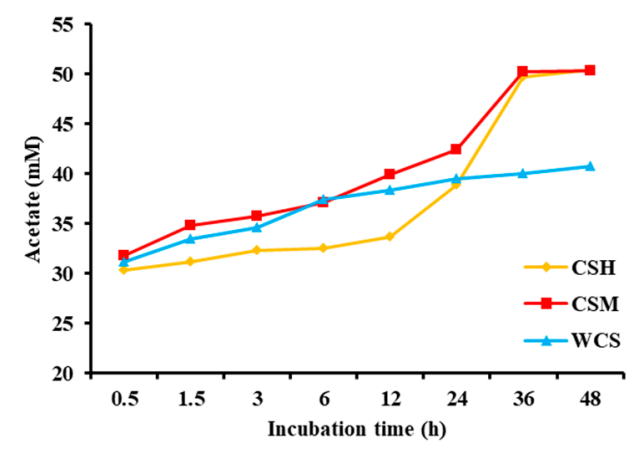

(a)

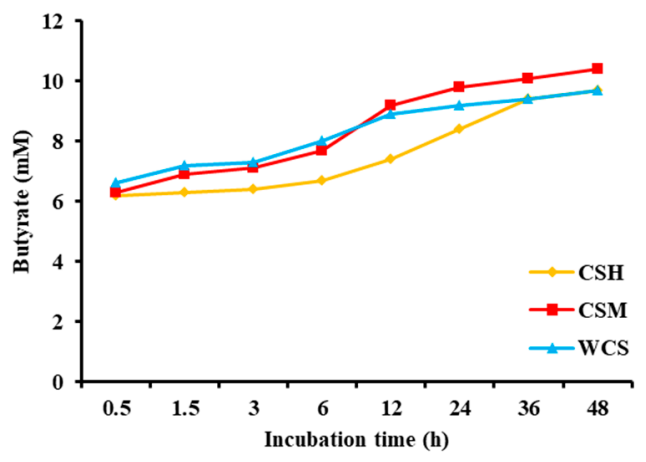

(c)

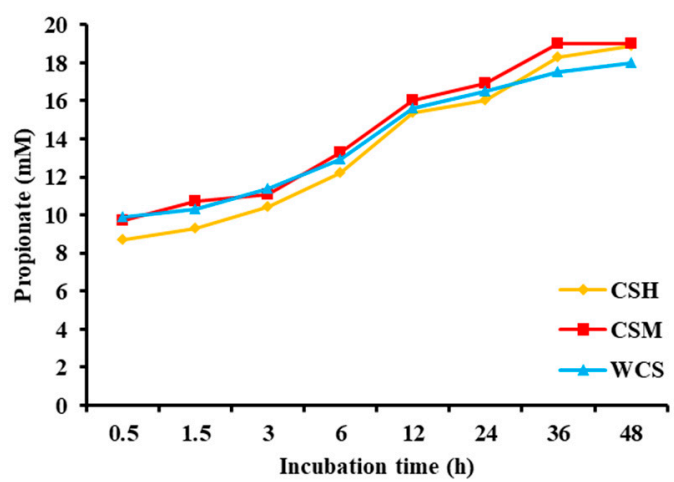

(b)

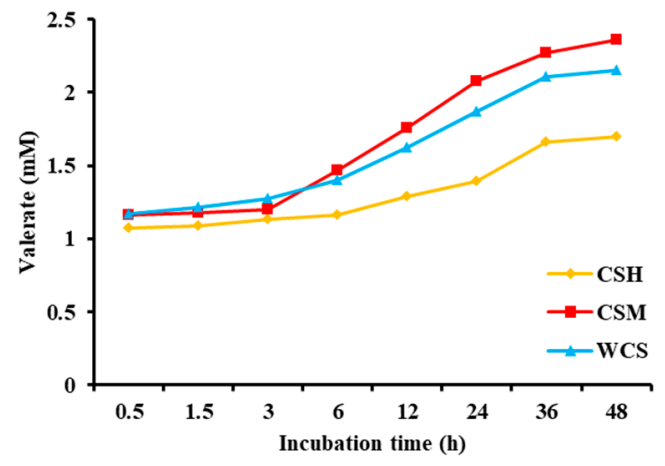

(d)

Figure 3. Cont. 


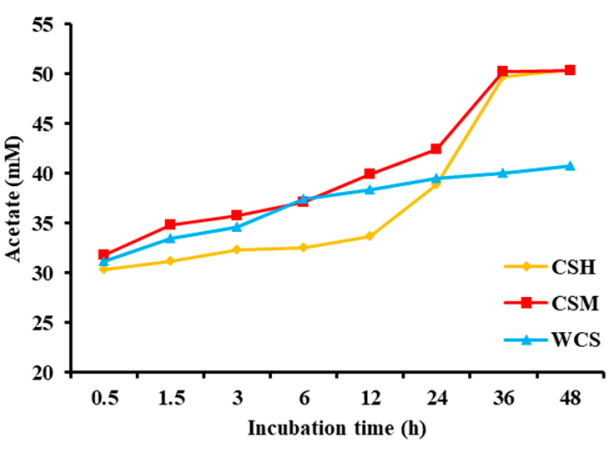

(a)

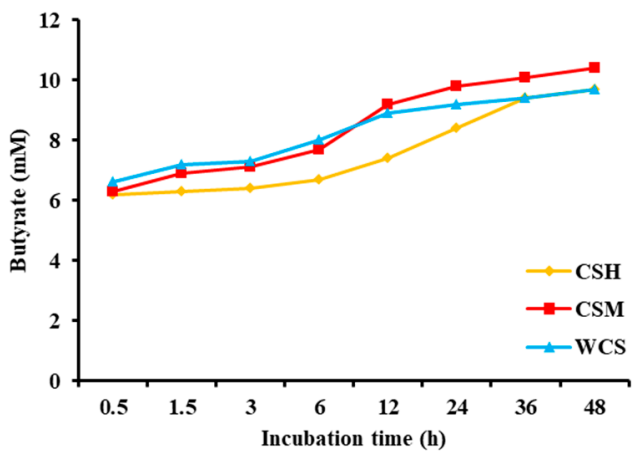

(c)

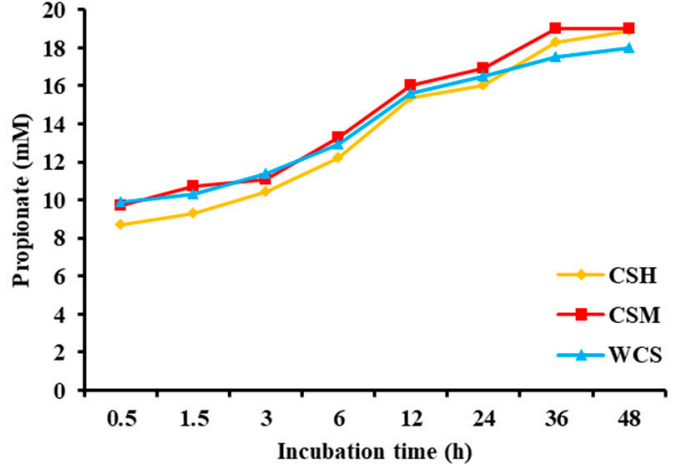

(b)

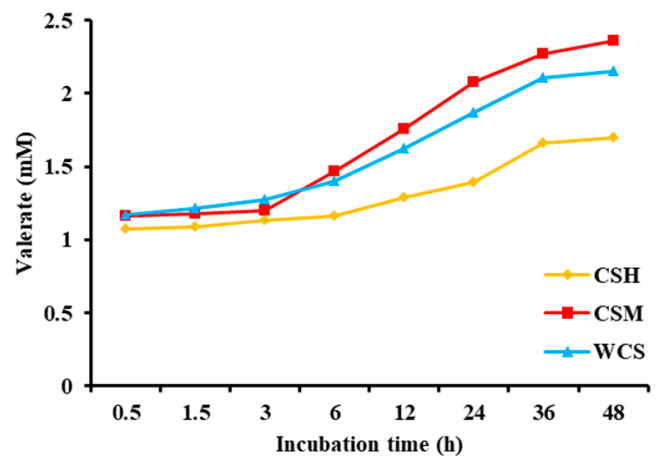

(d)

Figure 3. Rumen microbial fermentation characteristics of three kinds of samples: (a) acetate, (b) propionate, (c) butyrate, (d) valerate, (e) BCVFA, (f) NGR, and (g) FE. (h) Correlation analysis of tVFA and FG. BCVFA, branched volatile fatty acids; FE, fermentation efficiency; FG, free gossypol; NGR, the ratio of non-glucogenic to glucogenic acid; tVFA, total volatile fatty acid.

The average total VFA concentrations of CSH, CSM, and WCS reached 87.7, 90.5, and $78.4 \mathrm{mM}$ at $48 \mathrm{~h}$, respectively. There was no obvious difference of the propionate, BCVFA, and total VFA concentrations among three kinds of samples. All kinds of VFA production were greater in CSM than both WCS and CSH, and this was consistent with the results of the IVDMD and gas production, implicating that CSM presented a greater rumen fermentation efficiency. The total VFAs and ammonia $\mathrm{N}$ production of all the samples increased mainly during 6-36 h, suggesting that the activity of the rumen microorganisms was relatively higher during this period. According to the correlation analysis, there was an obvious negative correlation between the FG content and total VFAs $(r=-0.82, p=0.01)$, and the detrimental effect of FG on the total VFA production was more obvious when the gossypol content exceeded $2 \mathrm{~g} / \mathrm{kg}$ (Figure 3). In feeding trials, Ismartoyo [34] and Vinícius et al. [35] found that increasing the levels of WCS in rations linearly decreased the total VFA concentrations $(p<0.01)$, which was consistent with the present study. However, they considered that it was related with the reduction of the dry matter intake and did not investigate the effect of the gossypol intake from WCS.

Generally, VFAs are the main energy donor of ruminants, and the FE of energy from carbohydrates to VFAs was negative correlated with non-glucogenic fatty acid production and NGR. In the present study, WCS presented a higher FE of energy from carbohydrates to VFAs, which resulted from its lower acetate production compared to CSH and CSM. Meanwhile, NGR decreased when prolonging the incubation, which was consistent with the increase of FE (Figure 3). 


\subsection{Insights for Animal Health and Nutrition}

Cottonseed and its by-products are an important protein and energy feed source for ruminants; however, the toxicity of gossypol limits their amount and feeding value. An appropriate gossypol intake from rations is essential for the prevention of gossypol poisoning. In the present study, we found that gossypol originating from cottonseed and its by-products presented an obvious detrimental effect on cumulative gas production and total VFA production, especially when the gossypol content exceeded $2 \mathrm{~g} / \mathrm{kg}$. The European Union has stipulated that the safe gossypol content in the rations of adult ruminants should less than $0.5 \mathrm{~g} / \mathrm{kg}$ [36], which was much lower than our results, which noted that the rumen fermentation was affected when the gossypol content was over $0.5 \mathrm{~g} / \mathrm{kg}$. The gossypol content of the three WCS samples used in the present study ranged from $2.5 \mathrm{~g} / \mathrm{kg}$ to $8.0 \mathrm{~g} / \mathrm{kg}$. Consequently, we calculated WCS proportions in the rations of dairy cows that showed less than $20 \%$ based on a daily dry matter intake of $25 \mathrm{~kg}$.

In comparison with WCS and CSH, we found that CSM presented greater cumulative gas production and total VFA production, suggesting CSM had higher rumen fermentation efficiency, and this could be resulted from its higher CP content and lower FG content by the processing method. We suggest that using cottonseed by-products in the form of CSM in animal production could achieve better feeding effects.

\section{Conclusions}

Whole cottonseed presented lower cumulative gas and total volatile fatty acid production, while a cottonseed meal presented a greater total rumen degradation extent and rate. The highest fermentation efficiency of the energy from carbohydrates to volatile fatty acids occurred in whole cottonseed with the lowest non-glucogenic acetate production. Gossypol in cottonseed and its by-products showed relatively a lesser effect on the rumen degradability. However, there was a significant detrimental effect of gossypol on the rumen microbial fermentation efficiency, and such an effect was more pronounced when the gossypol content exceeded $2 \mathrm{~g} / \mathrm{kg}$. In brief, whole cottonseed exhibited mediocre rumen degradability and less microbial fermentation efficiency than cottonseed hulls and cottonseed meals, depending on their gossypol levels.

Author Contributions: Conceptualization, W.W. and Y.W.; methodology, W.W.; software, W.L. and F.Z.; validation, Q.W. and L.L.; formal analysis, W.W.; investigation, Y.W.; resources, W.L. and Q.W.; data curation, W.W.; writing—original draft preparation, W.W.; writing—review and editing, S.L. and H.Y.; visualization, H.Y.; supervision, H.Y.; project administration, H.Y.; and funding acquisition, S.L. All authors have read and agreed to the published version of the manuscript.

Funding: This research was funded by the Key Research and Development Project of the Ningxia Hui Autonomous Region, grant number 2018BBF33006.

Institutional Review Board Statement: The study was conducted according to the guidelines of the Declaration of Helsinki and approved by the Institutional Review Board of Institutional Animal Care Committee of China Agricultural University (protocol code: CAU20171014-1 and date of approval: 25 November 2021).

Informed Consent Statement: Not applicable.

Data Availability Statement: Not applicable.

Conflicts of Interest: The authors declare no conflict of interest.

\section{References}

1. Rogers, G.M.; Poore, M.H.; Paschal, J.C. Feeding cotton products to cattle. Vet. Clin. Food Anim. Pract. 2002, 18, 267-294. [CrossRef]

2. Brimer, L.; Sørensen, H. Gossypol as undesirable substance in animal feed-scientific opinion of the panel on contaminants in the food chain. EFSA J. 2009, 908, 1-55.

3. Risco, C.A.; Holmberg, C.A.; Kutches, A. Effect of graded concentrations of gossypol on calf performance: Toxicological and pathological considerations. J. Dairy Sci. 1992, 75, 2787-2798. [CrossRef] 
4. Zelski, R.Z.; Rothwell, J.T.; Moore, R.E.; Kennedy, D.J. Gossypol toxicity in preruminant calves. Aust. Vet. J. 1995, 72, 394-398. [CrossRef]

5. Alexander, J.; Benford, D.; Cockburn, A.; Cravedi, J.P.; Dogliotti, E.; Domenico, A.D.; Férnandez-Cruz, M.L.; Fürst, P.; FinkGremmels, J.; Galli, C.L.; et al. Scientific opinion gossypol as undesirable substance in animal feed scientific opinion of the panel on contaminants in the food chain. EFSA J. 2008, 6, 1-55.

6. Reiser, R.; Fu, H.C. The mechanism of gossypol detoxification by ruminant animals. J. Nutr. 1962, 76, 215-218. [CrossRef]

7. Chen, L.; Zhang, Y.; Chen, X.; Cheng, M.; Meng, X.; Cai, H. Gossypol Degradation Strain Coming from Ruminant Rumens and Application Thereof. 2015, CN 104328063A. Available online: https:/ / patents.google.com/patent/CN104328063A/en (accessed on 27 February 2022).

8. Zhang, Y.; Zhang, Z.; Dai, L.; Liu, Y.; Cheng, M.; Chen, L. Isolation and characterization of a novel gossypol-degrading bacteria Bacillus subtilis strain rumen bacillus subtilis. Asian-Australas. J. Anim. Sci. 2018, 31, 63-70. [CrossRef]

9. Wang, W.K.; Li, W.J.; Wu, Q.C.; Wang, Y.L.; Li, S.L.; Yang, H.J. Isolation and identification of a rumen Lactobacillus bacteria and its degradation potential of gossypol in cottonseed meal during solid-state fermentation. Microorganisms 2021, 9, 2200. [CrossRef]

10. Santos, J.; Villasenor, M.; Robinson, P.H.; DePeters, E.J.; Holmberg, C.A. Type of cottonseed and level of gossypol in diets of lactating dairy cows: Plasma gossypol, health, and reproductive performance. J. Dairy Sci. 2003, 86, 892-905. [CrossRef]

11. Chenoweth, P.J.; Chase, C.C., Jr.; Risco, C.A.; Larsen, R.E. Characterization of gossypol-induced sperm abnormalities in bulls Theriogenology 2000, 53, 1193-1203. [CrossRef]

12. Hassan, M.E.; Smith, G.W.; Ott, R.S.; Faulkner, D.B.; Firkins, L.D.; Ehrhart, E.J.; Schaeffer, D. Reversibility of the reproductive toxicity of gossypol in peripubertal bulls. Theriogenology 2004, 61, 1171-1179. [CrossRef]

13. Higginbotham, G.E.; Santos, J.E.P.; Depeters, E.J. Effects of pelleting whole cottonseed on plasma gossypol, rumen metabolites, and performance of lactating dairy cows. Prof. Anim. Sci. 2004, 20, 413-421. [CrossRef]

14. Câmara, A.C.L.; Gadelha, I.C.; Borges, P.A.; de Paiva, S.A.; Melo, M.M.; Soto-Blanco, B. Toxicity of gossypol from cottonseed cake to sheep ovarian follicles. PLOS ONE 2015, 10, e0143708. [CrossRef]

15. Yuan, Y.Y.; Shi, Q.X. Inhibition of hamster sperm acrosomal enzyme by gossypol is closely associated with the decrease in fertilization capacity. Contraception 2005, 62, 229-236. [CrossRef]

16. Wang, W.K.; Wang, Y.L.; Li, W.J.; Wu, Q.C.; Li, S.L.; Yang, H.J. In situ rumen degradation characteristics and bacterial colonization of whole cottonseed, cottonseed hull and cottonseed meal with different gossypol content. AMB Expr. 2021, 11, 91. [CrossRef]

17. Menke, K.H.; Raab, L.; Salewaki, A.; Steingass, H.; Fritz, D.; Schneider, W. The estimation of the digestibility and metabolizable energy content of ruminant feeding stuffs from the gas production when they are incubated with rumen liquor in vitro. J. Agric. Sci. 1979, 93, 217-222. [CrossRef]

18. Wang, W.K.; Wang, Y.L.; Li, W.J.; Wu, Q.C.; Li, S.L.; Yang, H.J. Gossypol exhibited higher detrimental effect on ruminal fermentation characteristics of low-forage in comparison with high-forage mixed feeds. Toxics 2021, 9, 51. [CrossRef] [PubMed]

19. Menke, K.H.; Steingass, H. Estimation of the energetic feed value obtained from chemical analysis and in vitro gas production using rumen fluid. Anim. Res. Dev. 1988, 28, 7-55.

20. AOAC. Official Methods of Analysis of AOAC International, 17th ed.; Association of Official Analytical Chemists: Gaithersburg, MD, USA, 2005.

21. Van Soest, P.J.; Robertson, J.B.; Lewis, B.A. Methods for dietary fiber, neutral detergent fiber, and nonstarch polysaccharides in relation to animal nutrition. J. Dairy Sci. 1991, 74, 3583-3597. [CrossRef]

22. Verdouw, H.; Vanechteld, C.J.A.; Dekkers, E.M.J. Ammonia determination based on indophenol formation with sodium salicylate Water Res. 1978, 12, 399-402. [CrossRef]

23. Ørskov, E.R.; McDonald, I. The estimation of protein degradability in the rumen from incubation measurements weighted according to rate of passage. J. Agric. Sci 1979, 92, 499-503. [CrossRef]

24. SAS. Statistical Analytical System (SAS) Users Guides: Statistics; Version 8.2; Statistica Analysis Institute: Cary, NC, USA, 1999.

25. Zhang, D.F.; Yang, H.J. In vitro ruminal methanogenesis of a hay-rich substrate in response to different combination supplements of nitrocompounds; pyromellitic diimide and 2-bromoethanesulphonate. Anim. Feed Sci. Technol. 2011, 163, 20-32. [CrossRef]

26. Cui, J.H.; Yang, H.J.; Yu, C.Q.; Bai, S.; Wu, T.T.; Song, S.S.; Sun, W.; Shao, X.M.; Jiang, L.S. Effect of urea fertilization on biomass yield, chemical composition, in vitro rumen digestibility and fermentation characteristics of straw of highland barley planted in Tibet. J. Agric. Sci. 2016, 154, 151-164. [CrossRef]

27. Raji, M.O.; Muraina, T.O.; Adebisi, I.A.; Akinosun, A.A.; Oyinlola, O.O.; Adeyemo, G.O. In vitro gas production and fermentative characteristics of cottonseed and cottonseed by-products. J. Biol. Agric. Health 2015, 5, 80-84.

28. Jouany, J.P.; Broudiscou, L.; Prins, R.A.; Komisarczuk-Bony, S. Métabolisme et nutrition de la population microbienne du rumen In Nutrition des Ruminants Domestiques; Jarrige, R., Ruckebusch, Y., Demarquilly, C., Farce, M.H., Journet, M., Eds.; Ingestion et digestion, INRA: Paris, France, 1995; pp. 349-381.

29. Repetto, J.L.; Cajarville, C.D.; Alessandro, J.; Curbelo, A.; Soto, C.; Garín, D. Effect of wilting and ensiling on ruminal degradability of temperate grass and legume mixtures. Anim. Res. 2005, 54, 73-80. [CrossRef]

30. Hou, C.X. The Effect of Gossypol on Rumen Microbial Population and Fiber Degradability; Inner Mongolia Agricultural University: Huhhot, China, 2012.

31. Bagheri, N.; Batistel, F. Effect of Different Cottonseed Types on Fiber Digestibility and Rumen Fermentation in a Continuous Culture System; ADSA-Annual Meeting: Louisville, KY, USA, 2021. 
32. Bergman, E.N. Glucose metabolism in ruminants as related to hypoglycemia and ketosis. Cornell. Vet. 1973, 63, 341-382.

33. Wang, C.D.; Li, Y.Q.; MaiTiSaiYiDi, T.; Yang, H.J.; Yang, K.L. Effect of dietary gossypol supplement on fermentation characteristics and bacterial diversity in the rumen of sheep. PLOS ONE 2020, 15, e0234378. [CrossRef]

34. Ismartoyo, M. Effect of feeding whole cottonseed as a supplement on digestibility and rumen fermentation characteristics of sheep. Bangladesh J. Anim. Sci. 2017, 46, 239-243. [CrossRef]

35. de Gouvêa, V.N.; Biehl, M.V.; de Castro Ferraz Juniorb, M.V.; Moreira, E.M.; Neto, J.A.F.; Westphalen, M.F.; Oliveira, G.B.; Ferreira, E.M.; Ferreira, D.M.; Pires, A.V. Effects of soybean oil or various levels of whole cottonseed on intake, digestibility, feeding behavior, and ruminal fermentation characteristics of finishing beef cattle. Livest. Sci. 2021, 244, 104390. [CrossRef]

36. Knutsen, H.K.; Barregård, L.; Bignami, M.; Brüschweiler, B.; Ceccatelli, S.; Dinovi, M.; Edler, L.; Grasl-Kraupp, B.; Hogstrand, C.; Hoogenboom, L.R.; et al. Presence of free gossypol in whole cottonseed. EFSA J. 2017, 15, 4850-4865. 